\title{
Metal ions modulate thermal aggregation of beta-lactoglobulin: A joint chemical and physical characterization
}

\author{
Giovanna Navarra ${ }^{\mathrm{a}}$, Anna Tinti ${ }^{\mathrm{b}}$, Michele Di Foggia ${ }^{\mathrm{b}}$, Maurizio Leone ${ }^{\mathrm{a}}$, \\ Valeria Militello ${ }^{a}$, Armida Torreggiani ${ }^{\mathrm{c}, *}$ \\ a Dipartimento di Fisica-Chimica, Università di Palermo, Via Archirafi 36, 90123 Palermo, Italy \\ b Dipartimento di Scienze Biomediche e Neuromotorie, Università di Bologna, Via Belmeloro 8/2, 40126 Bologna, Italy \\ c Istituto I.S.O.F., Consiglio Nazionale delle Ricerche, Via P. Gobetti 101, 40129 Bologna, Italy
}

\section{A R T I C L E I N F O}

\section{Article history:}

Received 5 February 2014

Received in revised form 2 April 2014

Accepted 2 April 2014

Available online 13 April 2014

\section{Keywords:}

Beta-lactoglobulin

Copper and zinc ions

Raman spectroscopy

Infrared spectroscopy

Dynamic light scattering

\begin{abstract}
A B S T R A C T
Molecular basis of the role played by $\mathrm{Cu}^{2+}$ and $\mathrm{Zn}^{2+}$ ions during the thermal aggregation processes of betalactoglobulin (BLG) was studied by using a joint application of different techniques. In particular, Raman spectroscopy was very useful in identifying the different effects caused by the two metals at molecular level (i.e. changes in His protonation state, disulfides bridge conformation, and micro-environment of aromatic residues), evidencing the primary importance of the protein charge distribution during the aggregation process. Both metal ions are able to act on this factor and favor the protein aggregation, but $\mathrm{Zn}^{2+}$ is able to alter the natural conformational state of BLG, causing a slight unfolding, whereas $\mathrm{Cu}^{2+}$ ions play a role only during the thermal treatment. Thus, $\mathrm{Zn}^{2+}$ ions favor the formation of bigger aggregates and branched fibril-like structures, whereas for $\mathrm{Cu}^{2+}$ ions a greater number of cross-beta structures during thermal incubation and finally, fibrillar structures. The aggregation process occurs in two phases, as suggested by the measurements on the time evolution of the BLG aggregates: the first one is characterized by a partial unfolding of the protein and aggregate growth, forming oligomers and protofibrils, whereas the second one is characterized by further supramolecular assembly, leading to the formation of fibrils.
\end{abstract}

(C) 2014 Elsevier Inc. All rights reserved.

\section{Introduction}

A large number of proteins may form under appropriate conditions a variety of aggregated structures whose morphology resembles those of fibrils that can be accumulated in biological environments under pathological conditions [1-4]. The fibril formation seems to be driven by an appropriate destabilization of the native state [1,5], and typical of the early phases of fibril formation is the conversion of $\alpha$-helices into $\beta$-sheets. However, also proteins containing a large fraction of $\beta$-sheets can be transformed in vitro into fibrillar structures through a process generally involving destabilization and consequent auto-assembly of partially unfolded intermediates. Fibrils are the final state of aggregated and re-organized protofibrils. The formation of amorphous aggregates, fibrils or gels may be initiated by thermal or chemically induced protein unfolding [6,7].

The formation of amorphous aggregates, fibrils or gels may be initiated by thermal or chemically induced protein unfolding [6,7].

Bovine $\beta$-lactoglobulin (BLG), a small globular protein of bovine milk, is made of 162 residues forming two antiparallel $\beta$-sheets [8]. Its

\footnotetext{
* Corresponding author at: Istituto ISOF (CNR), Via P. Gobetti n ${ }^{\circ} 101,40129$ Bologna, Italy. Tel.: + 39051 6399821; fax: + 390516399844.

E-mail address: armida.torreggiani@isof.cnr.it (A. Torreggiani).
}

known three-dimensional structure (Fig. 1) contains one free thiol group and it is stabilized by two disulfide bonds, Cys66-Cys160 and Cys106-Cys119, of which the first one generates a conformational restraint that is reported to inhibit the formation of misfolded aggregation of BLG [9].

BLG is one of the most popular model proteins in the study of protein folding and conformation in vitro. Refolding of denaturated BLG proceeds through a non-native $\alpha$-helical intermediate, making this protein a useful tool to investigate $\alpha-\beta$ transitions, important for example in the conformational transition of prion proteins. In addition, this protein can form either amorphous aggregates or amyloid fibrils upon changing the working parameter [10]. BLG, being the major whey protein in milk, is also important in food technological applications where the control of the protein denaturation/aggregation during heating is of outstanding importance for the acceptance of the final quality of the products and for avoiding allergenic problems [11]. Thus, we have selected BLG because of its double interest: it is a model beta-protein in aggregation processes and a thermal marker in industrial processes involved in milk treatment.

Although the mechanism of BLG heat-aggregation has been extensively studied, it is not still completely understood and controlled [7, 12-14]. As a consequence of BLG aggregation, either amorphous aggregates or amyloid fibrils can be formed, depending on the experimental conditions [12,15]. 
Metal ions can play a role in unfolding and/or aggregation processes thanks to their ability in acting as bridges of adjacent negatively charged groups, as well as by providing a shielding of negative charges of the neighboring protein molecules that, losing the repulsive forces, can get close enough to interact via non-covalent forces with a low potential energy $[12,16,17]$. The study of the interactions between metal ions and proteins is of increasing interest both in food processing, because of the capability of metal ions to induce cold gelation or aggregates $[18,19]$, and in biomedical sciences since the presence of metal ions, together with the amyloid fibril formation, is one of the fundamental aspects in the etiology of different neurodegenerative pathologies (amyloidosis) [20-22]. $\mathrm{Cu}^{2+}$ and $\mathrm{Zn}^{2+}$ ions have a different physiological role, and have been observed to promote aggregation in amyloid fibrils and/or amorphous aggregates. Moreover, they are important essential trace elements for human nutrition.

To get deep insight into the molecular basis of the fibril formation, it is interesting to know the effect of both metal ions on BLG aggregation, since the propensity of a protein to aggregate is correlated to many physico-chemical parameters, some of which can be affected by the metal/protein ratio and the metal ion binding mode. Here, we describe how $\mathrm{Cu}^{2+}$ or $\mathrm{Zn}^{2+}$ ions modulate the changes in the BLG structure caused by thermal treatment. A joint combination of techniques was used to obtain a more complete picture of the aggregation process mechanism at molecular level.

\section{Materials and methods}

\subsection{Sample preparation}

Bovine $\beta$-Lactoglobulin A (BLG A) was purchased from SigmaAldrich (A0281). The protein was dissolved in a $20 \mathrm{mM}$ MES (4morpholineethanesulfonic acid) buffer solution prepared in $\mathrm{H}_{2} \mathrm{O}$ or $\mathrm{D}_{2} \mathrm{O}(99.9 \%$, Aldrich) and titrated with $\mathrm{KOH}$ or KOD until pH or pD 7 (where $\mathrm{pD}$ is $\left.\mathrm{pH}_{\text {meter reading }}+0.4\right)$. The protein solution $(3.3 \mathrm{mM}$ ) was centrifuged for $8 \mathrm{~min}$ and filtered with Sartorius filters (pore diameter $0.20 \mu \mathrm{m}$ ). The samples, freshly prepared in $\mathrm{D}_{2} \mathrm{O}$, were divided in two aliquots for IR and DLS measurements, in order to characterize the heating phase (at $60{ }^{\circ} \mathrm{C}$ ) of the native protein solution. $\mathrm{D}_{2} \mathrm{O}$ solutions were used to avoid the IR spectral overlaps between the Amide I band and the strong water absorption at $1650 \mathrm{~cm}^{-1}$. $\mathrm{CuCl}_{2}$ or $\mathrm{ZnCl}_{2}$

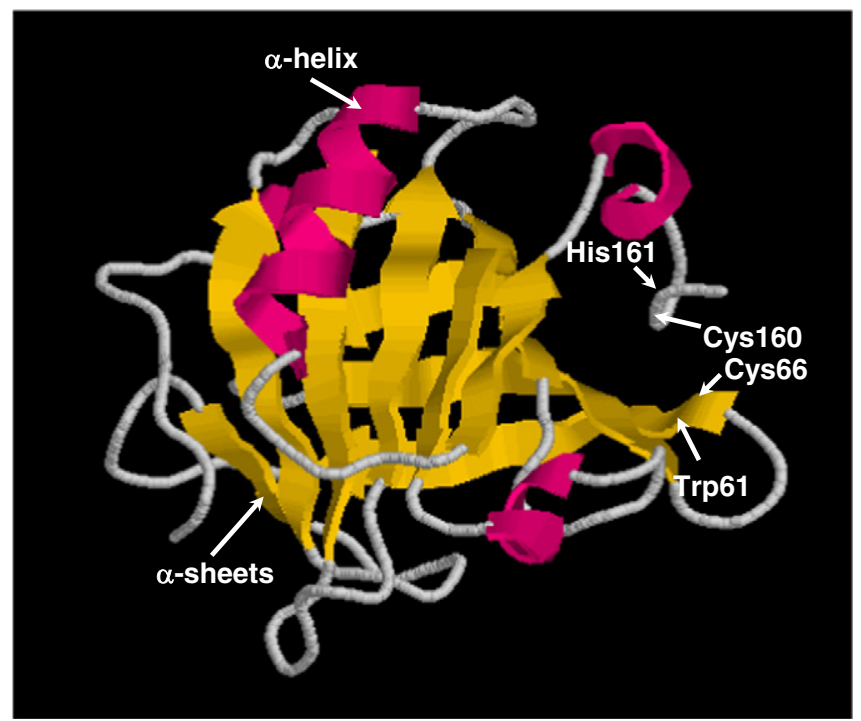

Fig. 1. Three-dimensional structure of BLG A that shows the relative positions of fou amino acid residues reasonably involved in the BLG aggregation process (Cys66-Cys160, His 161, and Trp61). The diagram was drawn from PDB file 1BSQ using RASMOL Ver.2.7.
(99.99\%, Sigma-Aldrich) was prepared in Super Q Millipore water and added to freshly prepared BLG solutions, in order to obtain a $1 \mathrm{mM}$ final concentration. The chloride salts of $\mathrm{Cu}^{2+}$ and $\mathrm{Zn}^{2+}$ were chosen for a spectroscopic reason, since they do not display any IR or Raman bands that can interfere with the protein spectrum. The freshly prepared samples in $\mathrm{H}_{2} \mathrm{O}$ were incubated at $60{ }^{\circ} \mathrm{C}$ for 400 min.

\subsection{Raman spectroscopy}

Raman spectra were obtained on lyophilised samples, before and after heating of the protein aqueous solution at $60^{\circ} \mathrm{C}$ for $400 \mathrm{~min}$, by a Bruker IFS 66 spectrometer equipped with a FRA-106 Raman module and a cooled Ge-diode detector. The excitation source was a $\mathrm{Nd}^{3+}$-YAG laser $(1064 \mathrm{~nm})$, the spectral resolution was $4 \mathrm{~cm}^{-1}$ and the total number of scans for each spectrum was 6000 . The laser power on the sample was about $100 \mathrm{~mW}$. Lyophilization was performed on a $4 \mathrm{~K}$ freeze dryer module equipped with a RV8 Rotary Vane Pump (Edwards). The lyophilized product was kept at $-80{ }^{\circ} \mathrm{C}$ until use.

The curve fitting analysis was implemented using the OPUS/IR v 5.0 program, which uses the Levenberg-Marquardt algorithm. In order to fit the vibrational bands, some parameters should be fixed or constrained within reasonable limits (number and position of all components). To obtain information regarding the number and position of the component peaks, smoothed fourth derivatives with a thirteenpoint Savitsky-Golay function, whose resolution is superior with respect to the second-derivative spectra, were used. The $\mathrm{S}-\mathrm{S}$ and secondary conformations, as well as the His tautomers, were estimated from the relative area of the individual components assigned to specific structural entities. The vibrational assignments of the band components were carried out on the basis of the literature. As regards the disulfide bridges, the components at about 505,520 and $540 \mathrm{~cm}^{-1}$ were assigned to the three basic conformations of $\mathrm{S}-\mathrm{S}$ bonds: gauche-gauche-gauche (ggg), gauche-gauche-trans (ggt) and trans-gauche-trans (tgt), respectively $[23,24]$. As regards the secondary structure, the $\alpha$-helix content of BLG was calculated from the area of the component in the $1652-1657 \mathrm{~cm}^{-1}$ range, whereas the contribution from unordered conformations was reflected by the $1661-1663 \mathrm{~cm}^{-1}$ peak [25]. $\beta$-Turns mainly gave rise to the bands in the $1639-1645$ and $1683-1695 \mathrm{~cm}^{-1}$ regions [26], whereas the components in the $1672-1678 \mathrm{~cm}^{-1}$ range were attributed to $\beta$-sheet conformation $[24,27]$.

An important assumption implicit in such an approach is that the effective intrinsic intensities of the bands corresponding to different conformations or side-chains are very similar. As a consequence, the curve fitting procedure cannot give the absolute content of a structure. However, the curve fitting analysis may be of value in probing the nature and the extent of structural changes in proteins induced by external factors interacting with protein molecules, such as free radical attack or heating treatment $[17,28]$.

\subsection{IR spectroscopy}

IR spectra were recorded by a Bruker Vertex 70 spectrometer, equipped with a mid-IR globar light source (a U-shaped silicon carbide piece). The spectral resolution was $2 \mathrm{~cm}^{-1}$ and the total number of scans for each spectrum was 100 . All samples were placed between two $\mathrm{CaF}_{2}$ windows, with a $0.05 \mathrm{~mm}$ Teflon spacer. The error on the wavenumber estimation was $\pm 1 \mathrm{~cm}^{-1}$ and the absorbance accuracy was within $1 \%$.

By using $\mathrm{D}_{2} \mathrm{O}$ in the preparation of protein solutions, it was possible to monitor the $\mathrm{H}-\mathrm{D}$ exchanges by means of the Amide II and the Amide II' bands. Amide II (or II') band (1400-1580 $\mathrm{cm}^{-1}$ ) is predominantly associated with the $\mathrm{N}-\mathrm{H}$ (or $\mathrm{N}-\mathrm{D}$ ) in-plane bending of the peptidic groups $[17,29,30]$. When $\mathrm{H}-\mathrm{D}$ exchange occurs, a simultaneous Amide II' increase and Amide II decrease are observed. In order to identify the evolution time of each spectral component under the broad amide bands, difference spectra were obtained by subtracting the 
spectrum at $t_{0}$ (where $t_{0}$ was the time needed to reach thermal equilibrium) to the spectrum at a generic $t$ time:

$\Delta A b s(t, v)=A b s(t, v)-A b s\left(\mathrm{t}_{0}, v\right)$.

This method allows to bring out the differences between the spectra and simultaneously to remove the constant contribution due to the $\mathrm{D}_{2} \mathrm{O}$ absorption. Moreover, Amide I and other specific infrared bands due to the vibration modes of some residues, such as His, Glu and Asp, were monitored.

\subsection{Dynamic light scattering (DLS)}

DLS measurements were performed by using a Nano-S Zetasizer (Malvern Instruments) equipped with a He-Ne laser source tuned at $633 \mathrm{~nm}$. Data were collected at $60{ }^{\circ} \mathrm{C}$ since at neutral $\mathrm{pH}$ the BLG unfolding starts at about $54{ }^{\circ} \mathrm{C}$ and the aggregation kinetics are too fast to be followed over $60{ }^{\circ} \mathrm{C}$. The sample compartment was completely self enclosed and the sample temperature was automatically controlled within $0.1{ }^{\circ} \mathrm{C}$. To compare these results with those obtained by IR spectroscopy, intensity scattering data were collected after a thermal equilibration time of $7 \mathrm{~min}$. Temperature scanning was performed at a $0.2{ }^{\circ} \mathrm{C} / \mathrm{min}$ rate.

The evolution of the BLG thermal aggregation in the absence and in the presence of metal ions was followed using a Malvern particle sizer, based on the light scattering theory. The UV/Vis absorption measurements, realized before and after thermal incubation, probed the absence of precipitate during the kinetics in all the investigated samples.

In order to obtain size information from the correlation function (see details in Navarra et al. [7]), two approaches were utilized: (a) fitting a single exponential to the correlation function to obtain the mean size (Z-average diameter), that is the weighted mean hydrodynamic size of the ensemble collection of particles measured by DLS (an increase in Z-average value is an index of particle aggregation); (b) fitting a multiple exponential to the correlation function to obtain the distribution of particle sizes (such as CONTIN analysis). The last analysis procedure allowed to obtain the distribution of the particle dimensions into protein solutions, based on the total light scattering intensity at different specific times of the whole kinetics.

\subsection{Fluorescence spectroscopy}

To probe the possible fibrillar growth during thermal treatment, fluorescence spectra were carried out at room temperature by a Jasco FP-6500 fluorimeter. Protein samples were monitored by means of thioflavin $\mathrm{T}$ (Th-T) fluorescence. Th-T is a fluorescent dye having a high selectivity for amyloid fibrils and its binding with such structures leads to an increase in its florescence intensity. $40 \mu \mathrm{M}$ Th-T dye solution was added to a BLG solution at $\mathrm{pH} 7$ and diluted to $33 \mu \mathrm{M}$ after heating. The Th-T fluorescence was measured in the 475-600 nm region [31] $\left(\lambda_{\text {exc }}=440 \mathrm{~nm}\right)$ at room temperature. All emission spectra were recorded with $0.5 \mathrm{~nm}$ wavelength intervals. Excitation and emission bandwidths were $5 \mathrm{~nm}$.

\subsection{Atomic force microscopy (AFM)}

In order to characterize the morphology of the supramolecular assemblies, AFM measurements were carried out on diluted aqueous solutions $(1: 200,000)$ obtained from heated protein solutions $(3.3 \mathrm{mM})$ in the absence and in the presence of $\mathrm{CuCl}_{2}$ or $\mathrm{ZnCl}_{2}(1 \mathrm{mM})$. All samples were diluted in bi-distilled demineralized water and imaged at room temperature. A small aliquot $(30 \mu \mathrm{l})$ of protein solution was deposited on freshly cleaved mica. The samples were dried overnight by a gentle nitrogen flux and imaged in air. The instrument used for the AFM measurements in tapping mode was a Veeco MultiMode V Scanning Probe Microscope. Etched-silicon probes with Al-coating on the detector side having a pyramidal-shaped tip with a nominal curvature $<10 \mathrm{~nm}$ were used. During scanning, the $125 \pm 10 \mu \mathrm{m}$ long cantilever, with a nominal spring constant in the range of $40 \mathrm{~N} / \mathrm{m}$, oscillated at its resonance frequency ( $330 \mathrm{kHz}$ ). Height, phase and amplitude error images were collected by capturing $512 \times 512$ points in each scan; the scan rate was maintained below 1 line per second. The worsening of the tips was monitored by using a test pattern before and after every measure session.

\section{Results and discussion}

\subsection{Heat-induced changes in specific protein moieties}

Raman spectroscopy gives useful information on the changes of the sulfur moieties in proteins, in particular in the $500-540 \mathrm{~cm}^{-1}$ region. BLG has five Cys residues, forming two disulfide bridges. The latter give rise to a band at $511 \mathrm{~cm}^{-1}$ and a shoulder at $500 \mathrm{~cm}^{-1}$ (Fig. 2(a)), indicating the presence of two $C_{\beta}-S-S-C_{\beta}{ }^{\prime}$ configurations, the ggt and the ggg, respectively. As a consequence of the thermal treatment, the $\mathrm{S}-\mathrm{S}$ configurations changed, as indicated by a slight intensity decrease in the $\sim 500 \mathrm{~cm}^{-1}$ component (Fig. 2(b)). The curve fitting analysis of this $\mathrm{S}-\mathrm{S}$ stretching region revealed that heating favors the two more opened $\mathrm{C}_{\beta}-\mathrm{S}-\mathrm{S}-\mathrm{C}_{\beta^{\prime}}$ configurations, ggt ( $30 \%$ ) and tgt ( $10 \%)$, whereas the preference towards the more energetically stable S-S conformation decreases ( $g g g$ from $80 \%$ to $\sim 60 \%$ ) (Fig. $3 \mathrm{~A}$ ). This trend was slightly enhanced in the presence of copper ions: in fact, about $40 \%$ of the disulfide bonds assumed the ggt and tgt configurations when BLG was heated (Fig. 3B). Conversely, zinc ions strongly favored the more opened $\mathrm{S}-\mathrm{S}$ configurations just before the heating treatment (ggt + tgt 50\% in Zn-BLG, whereas it was 25\% in Cu-BLG). Heating further increased this preference, making these configurations the prevalent ones (Fig. 3C).

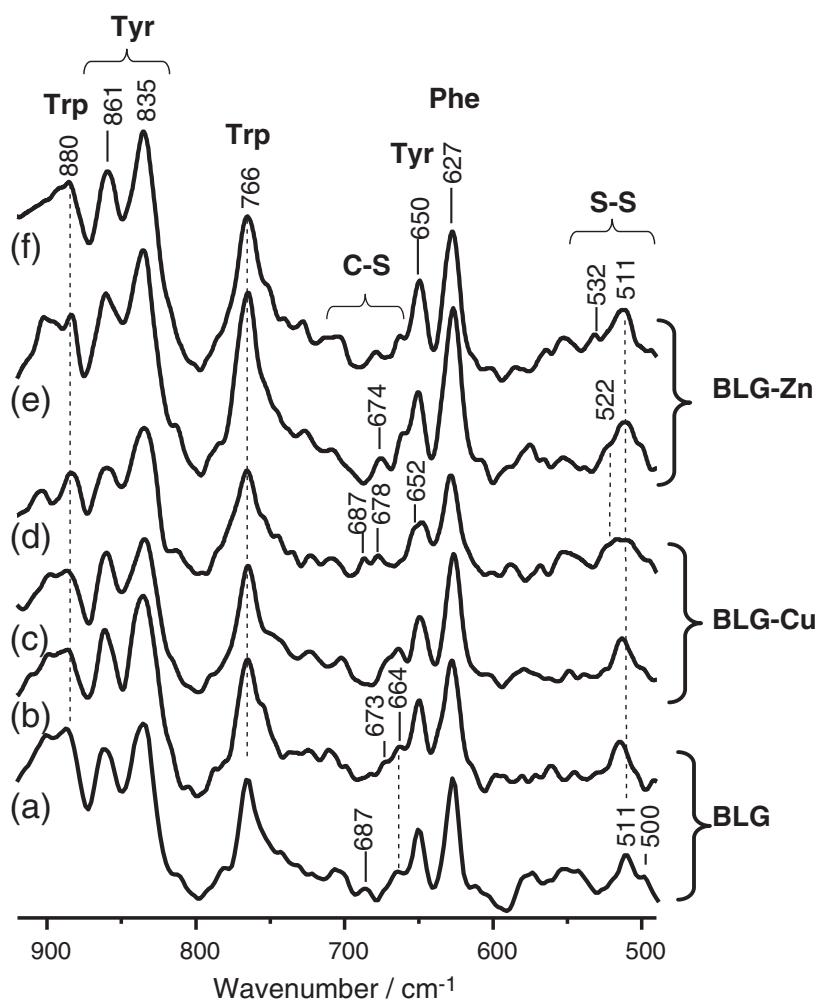

Fig. 2. The 920-490 $\mathrm{cm}^{-1}$ Raman region of BLG ((a) and (b)), Cu-BLG ((c) and (d)), and Zn-BLG ((e) and (f)), before and after thermal treatment, respectively. 
The disulfide conversion may be related not only to the protein conformational changes but also to a role played by $S-S$ disulfide bonds in the aggregation process. In particular, these results suggest a different role played by zinc and copper ions. Zinc ions are able to modify the natural conformational state of BLG, causing a slight unfolding of the tertiary structure before the heating treatment, whereas copper ions play a role during the heating, i.e. they could have a "promoter effect" on disulfide bond changes, through oxidation and sulfhydryl/disulfide exchange reactions, in agreement with the literature [32-34]. Unfortunately, it was not possible to obtain further information on intermolecular disulfide exchange because of the insufficient intensity of the $\mathrm{S}-\mathrm{H}$ band $\left(2570 \mathrm{~cm}^{-1}\right)$, that was not detected under our experimental conditions.

BLG contains two His residues (His-146 and His-161) whose role is worth investigating. In fact, the imidazole group of His side chain
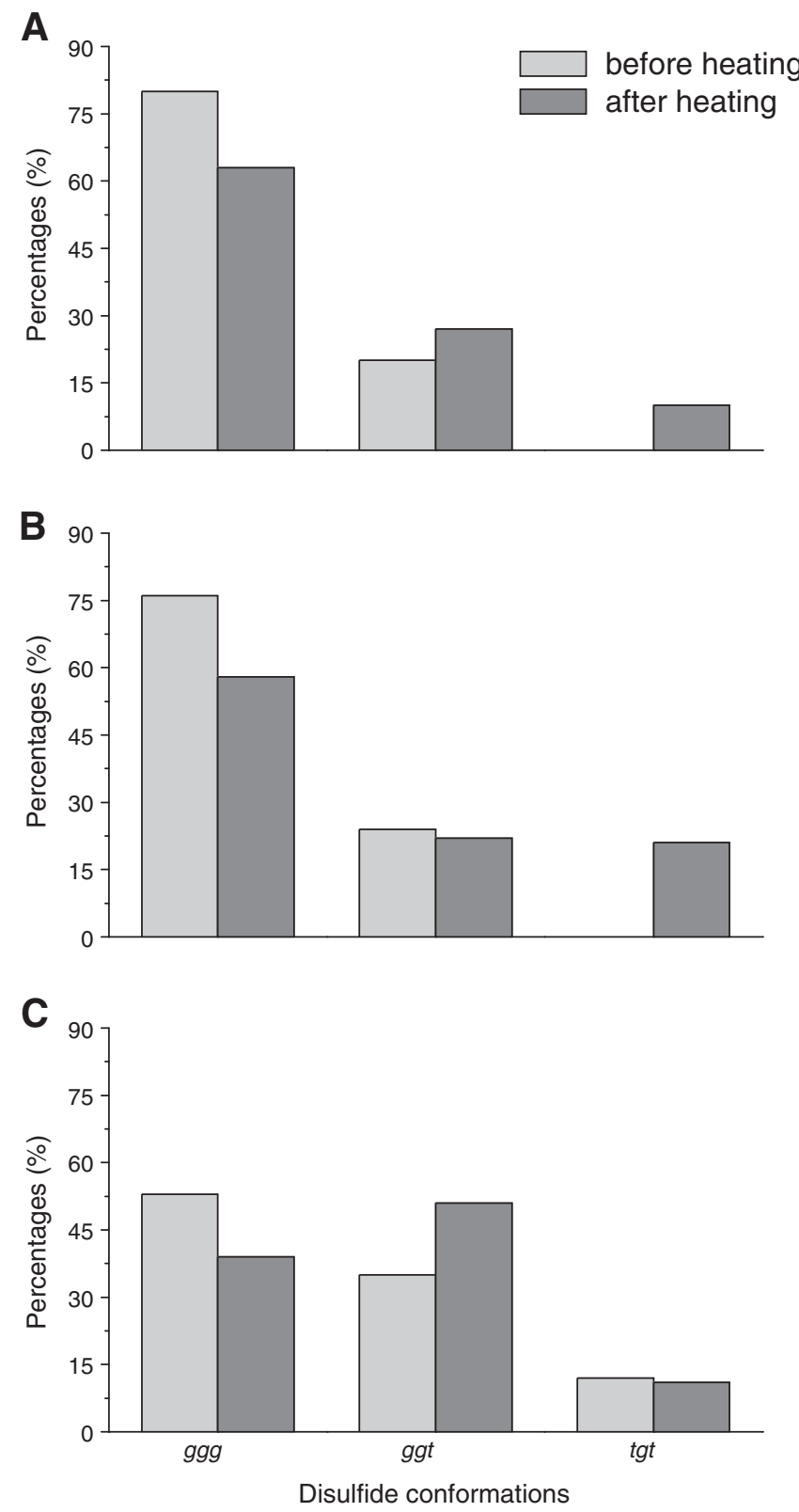

Fig. 3. Block diagram of the $\mathrm{S}-\mathrm{S}$ bridge conformations in (A) BLG, (B) Cu-BLG and (C) ZnBLG before and after thermal treatment. The percentages were calculated by the analysis of the 500-540 $\mathrm{cm}^{-1}$ Raman regions; ggg, ggt and tgt stand for gauche-gauche-gauche, gauche-gauche-trans and trans-gauche-trans conformations of the $C_{\beta}-S-S-C_{\beta^{\prime}}$ conformations. possesses two nitrogen atoms, which can be protonated or deprotonated. As a result, it takes four different protonation forms: two neutral tautomers, where one of the two nitrogen atoms is protonated $\left(\mathrm{N}_{1}-\mathrm{H}\right.$ and $\mathrm{N}_{3}-\mathrm{H}$ are tautomers I and II, respectively), fully protonated imidazolium cation $\left(\mathrm{His}^{+}\right)$, and imidazolate anion $\left(\mathrm{His}^{-}\right)$deprotonated at both the nitrogen sites:

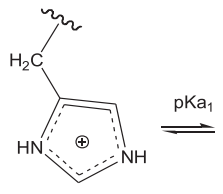

$\mathrm{His}^{+}$

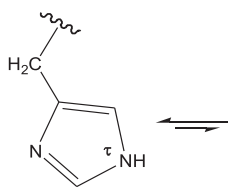

Taut (I)

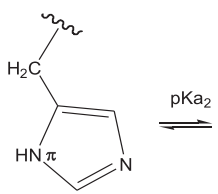

Taut (II)

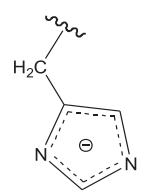

$\mathrm{His}^{-}$
In aqueous solution, the neutral $\mathrm{N}_{1}$ - and $\mathrm{N}_{3}$-protonated forms are in tautomeric equilibrium. Because the $\mathrm{pK}_{\mathrm{a}}$ of $\mathrm{His}^{+}$is around 6.0, His residue can undergo protonation/deprotonation reactions at neutral $\mathrm{pH}$. Therefore, owing to such a versatile nature, His can act as a protontransfer mediator by acting as a hydrogen-bond donor and/or acceptor, as observed in other various proteins [35,36]. Raman spectroscopy is one of the most powerful methods to study the protonation state of His in proteins since some bands, marker of the His tautomeric and ionic state, exist [37-39]. In particular, three Raman peaks (at 1570, 1290 and $990 \mathrm{~cm}^{-1}$ ) can be generally useful; among them, only the band at lower wavenumbers can be used in the case of BLG because of the overlapping with some Tyr and Phe bands (in the $1600-1560 \mathrm{~cm}^{-1}$ range) and with the amide III band (in the $1300-1240 \mathrm{~cm}^{-1}$ range). The band at $\sim 990 \mathrm{~cm}^{-1}$, due to the $=\mathrm{C}-\mathrm{H}$ in-plane bending vibration of the imidazole ring, is generally assumed as a marker of tautomer I (Taut (I)), whereas a higher wavenumber band $\left(\sim 1004 \mathrm{~cm}^{-1}\right)$ has been assigned to the other neutral tautomer [40]. If the histidyl moiety is in its cationic form, this band has been observed at $~ 996 \mathrm{~cm}^{-1}$ [41], whereas it shifted towards lower wavenumbers by metal coordination [41-44].

After heating, all samples showed a significant shift of the $987 \mathrm{~cm}^{-1}$ band towards higher wavenumbers, as well as an increase of its bandwidth (Fig. 4A). A curve fitting analysis of the $1040-950 \mathrm{~cm}^{-1}$ Raman range was performed to avoid the contribution from Phe residues. The Raman spectrum of native BLG exhibited four-five components of which one is attributable to Phe residues $\left(1009 \mathrm{~cm}^{-1}\right)$ and the others to the neutral forms of His (Fig. 4B). As indicated by the presence of the marker band at $\sim 990 \mathrm{~cm}^{-1}$, the two His residues in the native BLG are in the tautomeric I form (100\%) (Table 1). After the thermal treatment, Taut I remained the predominant form of the imidazole moiety, although also the cationic form of $\mathrm{His}\left(\mathrm{His}^{+}\right)$gave a small contribution $(\sim 10 \%)$ (Table 1 ), as suggested by a new component visible at $995 \mathrm{~cm}^{-1}$.

Tautomer I resulted to be preferred after the addition of both $\mathrm{Zn}^{2+}$ and $\mathrm{Cu}^{2+}$ ions. In the presence of the latter, a new peak component appeared at $\sim 967 \mathrm{~cm}^{-1}$, indicating a partial involvement of His in the metal coordination $(\sim 10 \%)$ (Table 1$)$. This result is in agreement with the literature where $\mathrm{Cu}^{2+}$ is reported to be, at least partially, bound to the protein native state by means of a binding with the His residues, similar to what is observed in bovine serum albumin [17] and in $\beta$ microglobulin $[45,46]$.

Tautomer I resulted to be preferred also after the $\mathrm{Zn}^{2+}$ addition (Fig. $4 \mathrm{~B}(\mathrm{a})$ ). After heating, the trend was similar both in the presence and in the absence of metal ions (Table 1). The component due to the $\mathrm{His}^{+}$form (at $\sim 996 \mathrm{~cm}^{-1}$ ) appeared in all systems (as an example, see Fig. $4 \mathrm{~B}(\mathrm{~b})$ and $\mathrm{B}(\mathrm{c})$ ), although its contribution was more relevant in the presence of $\mathrm{Zn}^{2+}$ ions (about 30\% - Table 1). Since in the BLG sequence one of the two His residues (His161) is close to the disulfide bridge (Cys66-Cys160) (see Fig. 1) reported to play an important role in stabilizing the dimeric native state of the protein, this result can be connected with the different modifications induced by the metal ions on the disulfide bridge conformations. In fact, the more opened S-S 
conformation favored by $\mathrm{Zn}^{2+}$ ions before heating, could also favor the successive His protonation.

The change in the protonation state of some His residues points out the importance of the protein charge on the BLG stabilization and, of consequence, on the thermal-induced aggregation process of BLG. Both metal ions are able to act on the protein global charge, but $\mathrm{Zn}^{2+}$ ion seems to be the most efficient in affecting the charge redistribution on the protein. This aspect may be a key step to understand the different effects of the two metal ions on the protein aggregation process, since the aggregation in the presence of $\mathrm{Zn}^{2+}$ could be promoted by the screening of electrostatic interactions between charged protein molecules.

BLG contains many charged amino acid side chains (16 Glu, 11 Asp, 15 Lys and 3 Arg residues), contributing to the stabilization of the protein structure. The ability of $\mathrm{Cu}^{2+}$ and $\mathrm{Zn}^{2+}$ ions in modifying ionic interactions inside the protein during heating was further confirmed by the significant spectral changes, particularly evident in the difference spectrum of Zn-BLG system (Fig. 5), in the $1400-1430 \mathrm{~cm}^{-1}$ region, where the carboxylic groups of acid side chains mainly contribute [47]. This behavior suggests heat-induced variations in the bond networks involving these functional groups, favored by metal ions. These changes were further confirmed by Tyr residues whose tyrosyl $\mathrm{OH}$ groups resulted to be more strongly hydrogen bonded to a negative acceptor after heating, as suggested by the decrease in the ratio of the tyrosyl doublet at $\sim 860$ and $835 \mathrm{~cm}^{-1}\left(\mathrm{I}_{860} / \mathrm{I}_{835}\right)$, occurring in all the heated samples (Fig. 2). This ratio is a good indicator of the hydrogen bonding involving the $\mathrm{OH}$ group of Tyr and decreases when the phenolic hydroxyl oxygen is ionized or strongly hydrogen bonded to a negatively charged acceptor, such as a carboxylate ion in Asp and Glu residues [25,
Table 1

Percentages of the neutral, protonated and metal-coordinated histidyl moiety obtained by the curve fitting analysis of the $1030-950 \mathrm{~cm}^{-1}$ Raman spectral range. The position of the band components, markers of the different His forms, are indicated into the brackets.

\begin{tabular}{|c|c|c|c|c|}
\hline \multirow[b]{2}{*}{ Samples } & & Relative & Integrated & Intensity (\%) \\
\hline & & $\begin{array}{c}\text { His }^{+} \\
\left(997 \pm 1 \mathrm{~cm}^{-1}\right)\end{array}$ & $\begin{array}{c}\text { Taut I } \\
\left(990 \pm 2 \mathrm{~cm}^{-1}\right)^{\mathrm{a}}\end{array}$ & $\begin{array}{c}\text { His-M } \\
\left(968 \pm 1 \mathrm{~cm}^{-1}\right)\end{array}$ \\
\hline \multirow[t]{2}{*}{ BLG } & Untreated & - & $100 \%$ & - \\
\hline & Heated & $11 \%$ & $89 \%$ & - \\
\hline \multirow[t]{2}{*}{ Cu-BLG } & Untreated & - & $91 \%$ & $9 \%$ \\
\hline & Heated & $18 \%$ & $71 \%$ & $11 \%$ \\
\hline \multirow[t]{2}{*}{ Zn-BLG } & Untreated & - & $100 \%$ & - \\
\hline & Heated & $27 \%$ & $73 \%$ & - \\
\hline
\end{tabular}

${ }^{a}$ I standing for His tautomer I (N1-H).

48]. Thus, also some of the four Tyr residues take part to the protein stabilization by creating stronger hydrogen bonds.

BLG has two Trp residues: the indole ring of Trp19 is completely buried while that of Trp61 can be exposed to a polar environment, since it is located in a mobile loop [32] (Fig. 1). Exposure of buried Trp residues in proteins is indicated by the intensity decrease of the $\sim 760 \mathrm{~cm}^{-1}$ Raman band [49]; this band showed a weak intensity decrease, more evident in the presence of $\mathrm{Zn}^{2+}$ ions, in all the heated samples (Fig. 2(e) and (f)), indicating a partial exposition of Trp to the solvent. The modifications in the Trp micro-environment can be connected with the changes occurring in the disulfide conformations (see above). In fact, among the two Trp residues of BLG, it seems reasonable to assume that Trp19 remains buried whereas Trp61 can move into a more polar environment. Trp61 is quite close to the Cys66-Cys160 disulfide bond. Therefore,

A

B

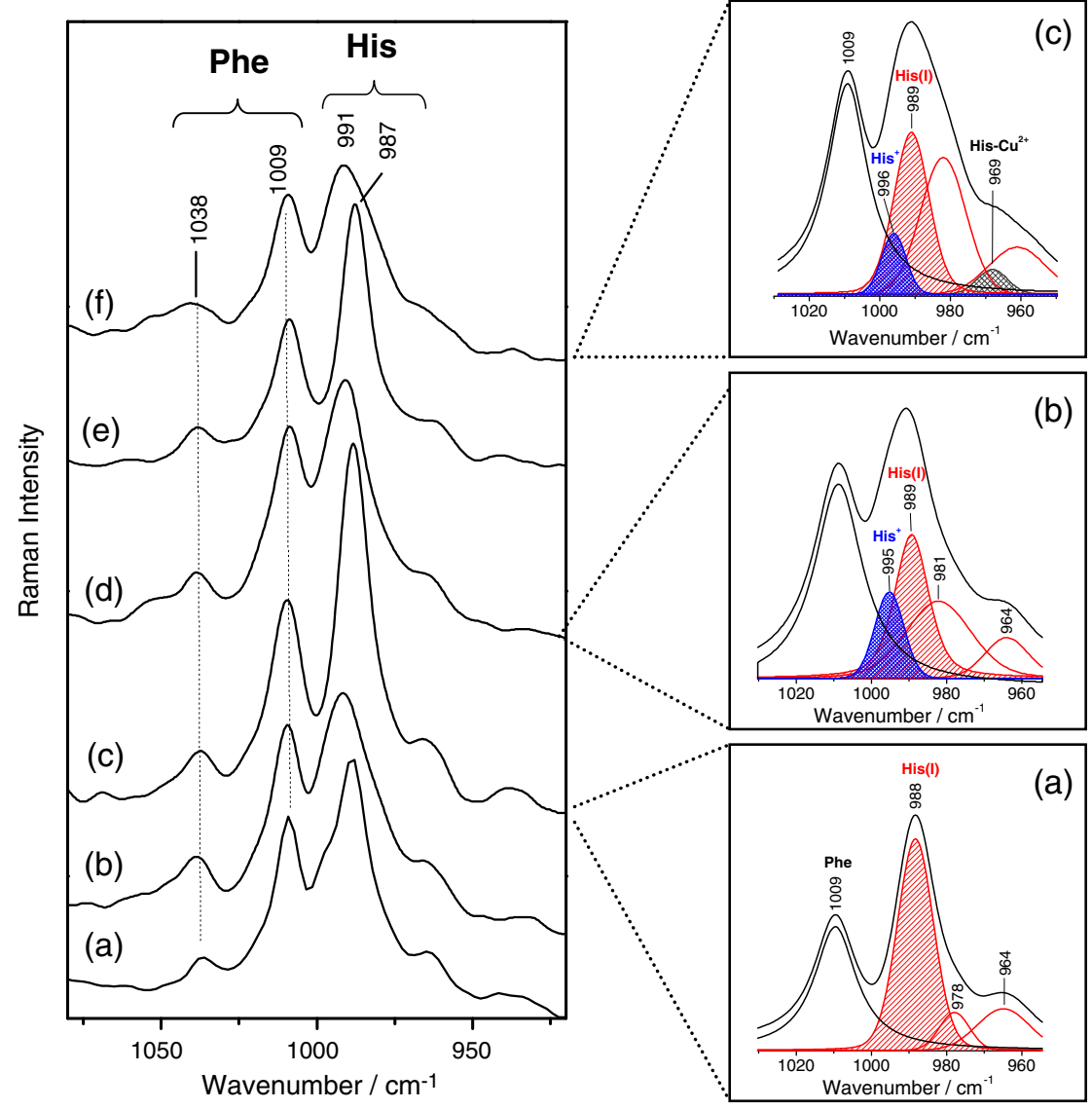

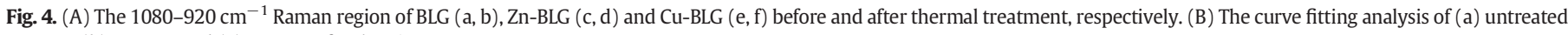
Zn-BLG; (b) Zn-BLG and (c) Cu-BLG after heating. 
the presence of $\mathrm{Zn}^{2+}$ ions, that favors a more opened S-S conformation before heating, could also induce a more relevant exposition of Trp on the surface. Also the change in the Trp micro-environment can play a role in the aggregation process, since it alters the protein hydrophobic interactions.

\subsection{Heat-induced changes in backbone conformations}

As it is well known, one of the potential advantages of Raman spectroscopy for the study of proteins lies in the correlation between the vibrational frequencies of the peptide backbone and the various protein conformations. The most used bands for the secondary structure determination are the amide I band, due to the stretch vibration of the peptide $C=0$ group $\left(1640-1700 \mathrm{~cm}^{-1}\right)$, and the amide III band (1240-1300 $\mathrm{cm}^{-1}$ ), resulting from coupled Raman active $\mathrm{C}-\mathrm{N}$ stretching and $\mathrm{N}-\mathrm{H}$ bending motions.

Both amide I and amide III bands of the BLG spectra, being at 1672 and $\sim 1245 \mathrm{~cm}^{-1}$, respectively (Fig. 5 and Fig. S1 in Supplementary information), indicated that it has a prevailing $\beta$-sheet structure both in the absence and the presence of metals, as expected from the literature [50]. The thermal treatment induced an increase in the $\beta$-sheet content in all samples, as well as a decrease in the non-ordered structures, indicated by the Amide I band shift towards higher wavenumbers and the decrease in its full width at half maximum (FWHM) (Table S1 in Supplementary information). This qualitative result was confirmed by the analysis of the difference spectra, obtained by subtracting the Raman spectra of the unheated samples from those of the heated ones. In fact, two positive bands at $\sim 1235 \mathrm{~cm}^{-1}$ (Amide III) and at $\sim 1050 \mathrm{~cm}^{-1}$ (marker of $\beta$-sheet conformation) appeared (Fig. 5). To obtain a semiquantitative evaluation of the conformational changes upon heating, a curve fitting analysis of the Amide I region was performed. The BLG spectra before and after treatment exhibited seven-eight components resulting from the contribution of the different secondary structure elements. The native BLG was found to contain mainly $\beta$-sheets (52\%), that is consistent with the previous reports obtained by vibrational spectroscopy (Table 2) [50]. Heating treatment caused a significant increase in the $\beta$-sheet content (more than $20 \%$ ), whereas the $\beta$-turn motifs strongly decreased ( 35\%). The trend was the same for all samples. It's worth pointing out that the addition of $\mathrm{ZnCl}_{2}$ to native $\mathrm{BLG}$, differently from $\mathrm{CuCl}_{2}$, slightly altered the protein conformation just before the thermal treatment (Table 2).

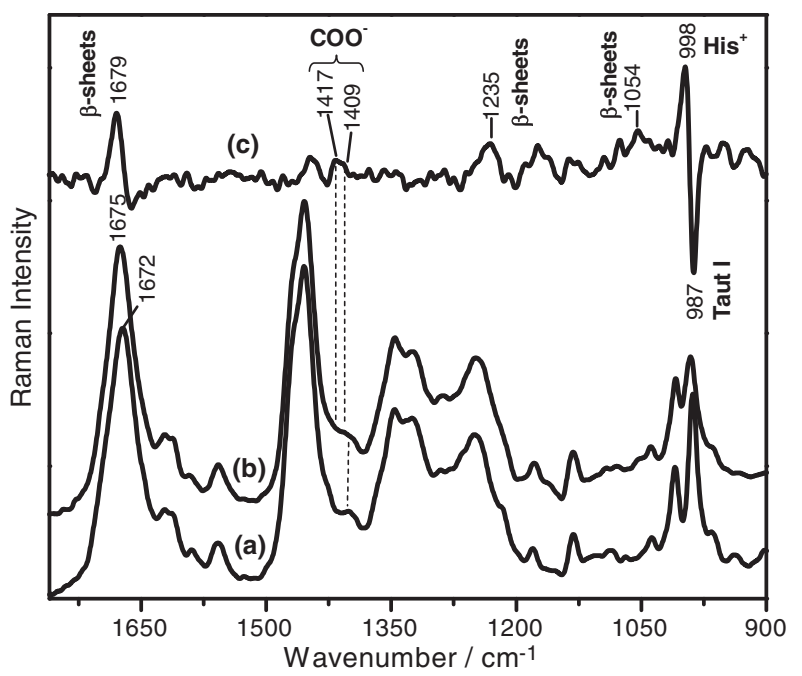

Fig. 5. Raman spectra of the Zn-BLG system: (a) before thermal treatment; (b) after thermal treatment; (c) difference spectrum obtained by subtracting spectrum (a) from spectrum (b).
Table 2

Percentages of secondary structures present in native BLG and the two metal-BLG systems before and after heating, obtained by the curve fitting analysis of the Raman Amide I region.

\begin{tabular}{llllll}
\hline \multirow{2}{*}{ Samples } & \multicolumn{4}{l}{ Percentages (\%) } \\
\cline { 3 - 6 } & & $\alpha$-Helix & $\beta$-Sheet & $\beta$-Turns & Random \\
\hline \multirow{2}{*}{ BLG } & Untreated & 10 & 52 & 25 & 13 \\
& Heated & 8 & 64 & 16 & 12 \\
\multirow{2}{*}{ Cu-BLG } & Untreated & 9 & 49 & 27 & 15 \\
& Heated & 8 & 62 & 16 & 14 \\
\multirow{2}{*}{ Zn-BLG } & Untreated & 6 & 56 & 21 & 17 \\
& Heated & 8 & 68 & 13 & 11 \\
\hline
\end{tabular}

\subsection{Time evolution of heat-induced structural changes}

Infrared kinetics were performed during protein incubation to obtain information on the time evolution of the protein conformational changes. Two different phases were revealed: the first one was characterized by spectral changes in the Amide I band, whereas the second by modifications both in the water-related bands and in a weak band visible at about $1725 \mathrm{~cm}^{-1}$ that increases in intensity. Initially, changes in secondary structure occur and $\beta$-aggregated structures are formed. In fact, the time evolution of the difference spectra indicated the growth of parallel $\beta$-aggregated structures from antiparallel intramolecular beta sheets, in agreement with the literature [12]. This result was probed by the intensity increase of the difference bands at 1621 and $1628 \mathrm{~cm}^{-1}$ ( $\beta$-aggregates) and the contemporaneous intensity decrease in those at about 1638 and $1685 \mathrm{~cm}^{-1}$ (antiparallel intramolecular $\beta$-sheets), and at about $1650 \mathrm{~cm}^{-1}$ due to $\alpha$-helix structures (Fig. S2 in Supplementary information). The typology of conformational changes occurring during the first aggregation phase is the same in all the three systems and metal ions affect only the duration of this phase (concluded within $~ 30$ min for Cu-BLG and Zn-BLG), as shown by the time evolution of the intensity of the $1621 \mathrm{~cm}^{-1}$ band, marker of the $\beta$-aggregated structures (Fig. 6 ). The aggregate growth, higher in the $\mathrm{Cu}-\mathrm{BLG}$ system than in the other two, is in agreement with the differences observed in the secondary structure percentages of Cu-BLG before heating with respect to those of BLG and Zn-BLG (Table 2).

As regards the time length of the first phase, it was concluded within $\sim 30 \mathrm{~min}$ in the $\mathrm{Cu}-\mathrm{BLG}$ and $\mathrm{Zn}$-BLG systems. The second phase starts when the formation of intermolecular $\beta$-sheets is in the initial part of a plateau zone, indicating that this phase is a process depending on the aggregative state in solution and not on the protein single molecule conformation (Fig. 6).

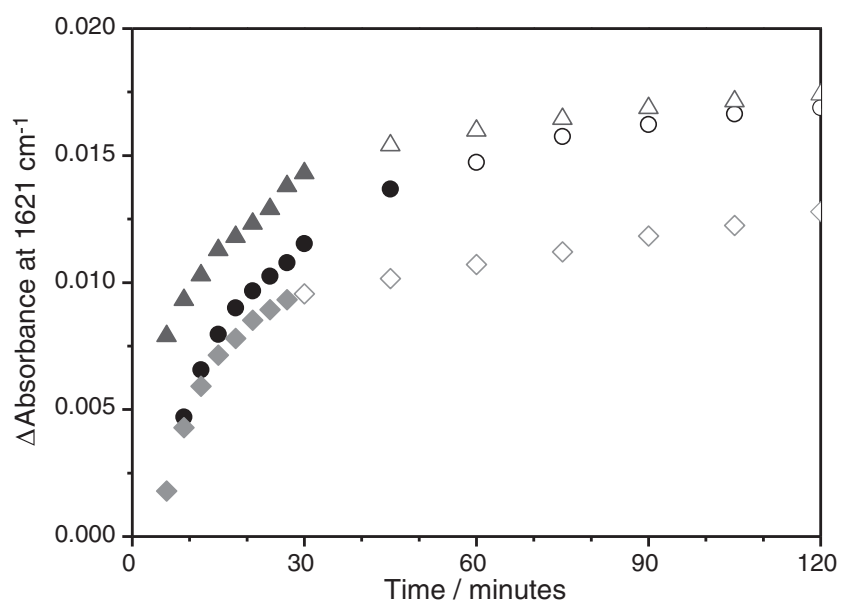

Fig. 6. Evolution time of the Amide I' difference intensity at $1621 \mathrm{~cm}^{-1}$ for BLG (black circle), Cu-BLG (dark gray triangle) and Zn-BLG (gray rhombus); data concerning the first phase are shown with full symbols. 
By following the $\mathrm{H}-\mathrm{D}$ exchange process between protein and solvent, in particular the time evolution of Amide II $\left(1546 \mathrm{~cm}^{-1}\right)$ and Amide $\mathrm{II}^{\prime}\left(1435 \mathrm{~cm}^{-1}\right)$ bands, due to $\mathrm{N}-\mathrm{H}$ and $\mathrm{N}-\mathrm{D}$ in-plane bending of the peptidic groups, respectively, the presence of two phases was evident (Fig. 7). Initially, the intensity of the Amide II band decreased

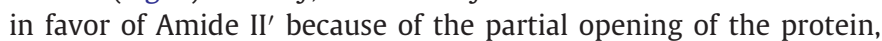
which favors the $\mathrm{H}-\mathrm{D}$ exchange, and, of consequence, the decrease of $\mathrm{NH}$ groups in favor of ND ones; then, the intensity of the $1546 \mathrm{~cm}^{-1}$ band increased (Fig. 7B). However, the BLG partial unfolding was substantially concluded during the first phase (at the most within the
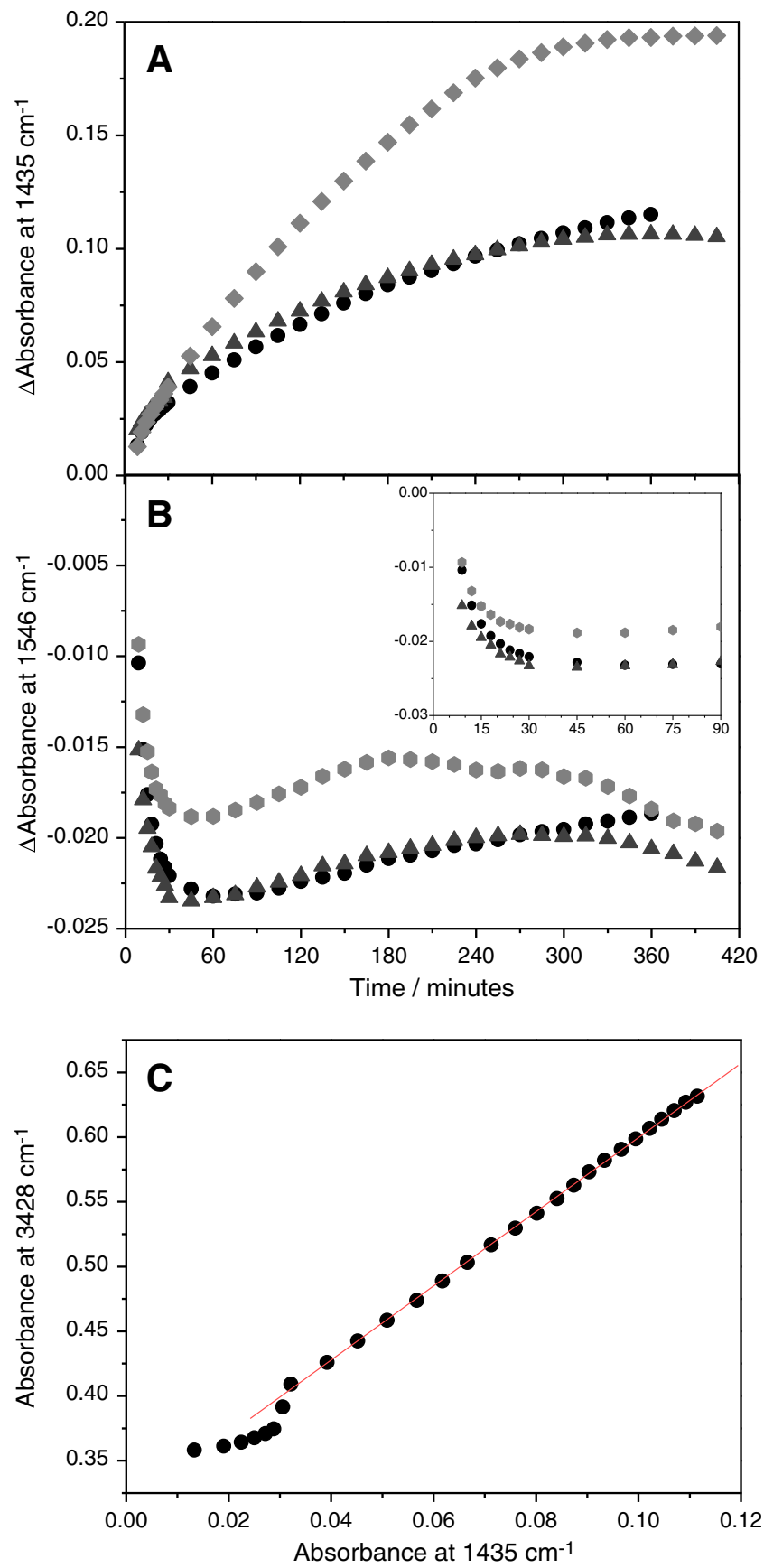

Fig. 7. Time evolution of the IR absorption difference spectra (A) at $1435 \mathrm{~cm}^{-1}$ (Amide II') and (B) at $1546 \mathrm{~cm}^{-1}$ (Amide II) for BLG (black circle), Cu-BLG (dark gray triangle), and Zn-BLG (gray rhombus). In the inset an enlargement of the first 90 min of the thermal kinetics is reported. (C) Correlation between the modifications in the intensity of the bands at 3428 and $1435 \mathrm{~cm}^{-1}$ during the thermal kinetics. The line is the result of a linear fit of data belonging to the second phase of the IR kinetics. first $50 \mathrm{~min}$ ), as shown in the inset of Fig. 7B, where the first min of the kinetics is visible.

It has been generally accepted that the rate of $\mathrm{H}-\mathrm{D}$ exchange and the exchange extent at a given time depend on the structural mobility of protein. The more mobile (less rigid) the protein structure, the faster the rate of $\mathrm{H}-\mathrm{D}$ exchange. A more rapid partial opening of the protein structure occurred both in Cu-BLG and Zn-BLG samples, since the plateau was reached in about $30 \mathrm{~min}$, instead of $50 \mathrm{~min}$ (Fig. 7B).

In the $\mathrm{Zn}$-BLG sample a lower number of $\mathrm{NH}$ groups disappeared in favor of ND ones. This result can be explained by considering either that the unfolding process occurs in a lesser extent during heating or that a partial unfolding is induced by metal ions before the protein incubation. The last explanation is consistent with the Raman data on the secondary structures (see above); thus, the presence of $\mathrm{Zn}^{2+}$ in solution, altering the native tertiary structure of the protein, causes a partial conversion of $\mathrm{NH}$ groups into $\mathrm{ND}$ ones before the protein incubation.

As regards the second kinetic phase, the simultaneous increase in the intensities of the Amide II and Amide II' bands (Fig. 7A and B) was not attributed to an $\mathrm{H} / \mathrm{D}$ exchange process, although they could indicate the occurrence of changes in protein tertiary structure. In fact, the intensity increase of Amide II' $\left(1435 \mathrm{~cm}^{-1}\right)$ can be due to an increase in the number of HOD groups rather than to an increase of ND groups, since the band due to the bending vibration of the HOD molecule $\left(1430 \mathrm{~cm}^{-1}\right)$ overlaps with Amide II'. A further confirmation was given by the intensity of the DOD bending vibration $\left(1200 \mathrm{~cm}^{-1}\right)$ which was found to decrease (Fig. S3 in Supplementary information). Indeed, for BLG a linear

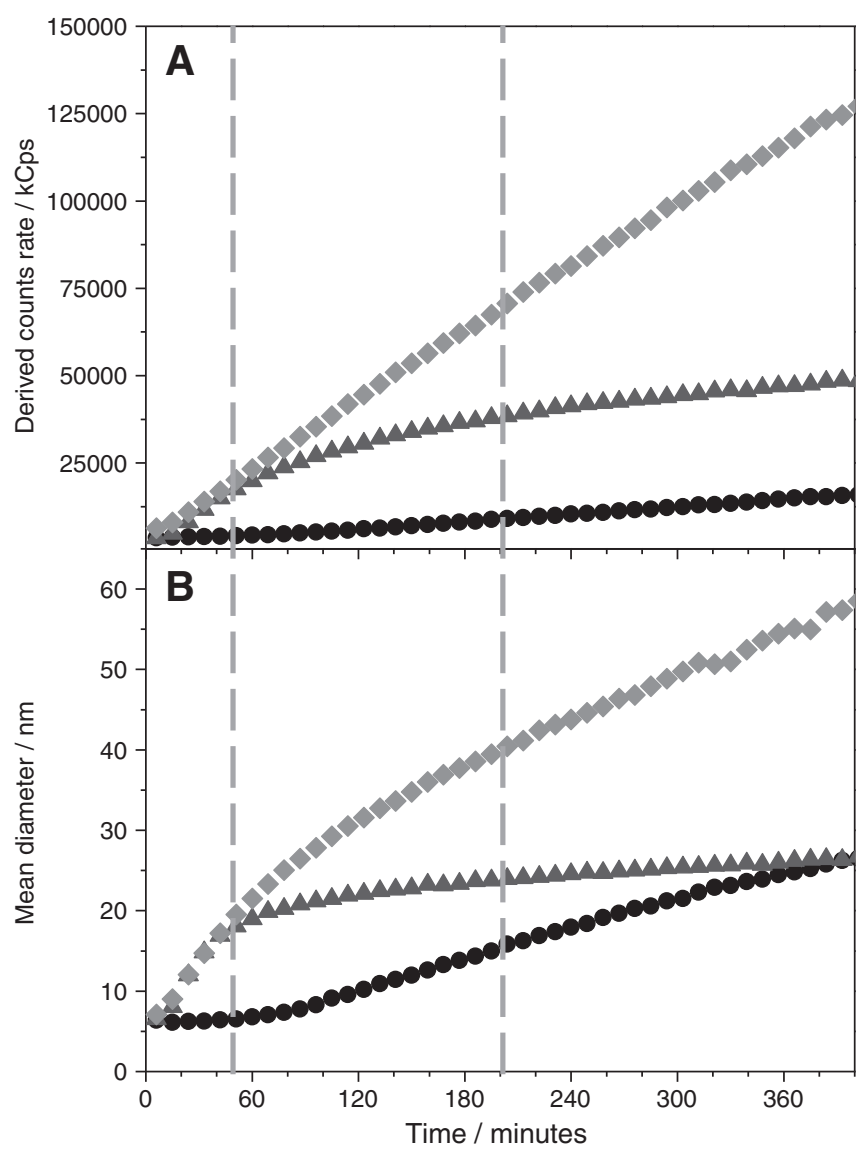

Fig. 8. Time evolution of (A) the scattering light intensity and (B) the mean diameter of the particles in solution in BLG (black circle), Cu-BLG (dark gray triangle), Zn-BLG (gray rhombus) samples. The $\mathrm{pH}$ value was 7 and the temperature was $60{ }^{\circ} \mathrm{C}$. The experimental error is smaller than symbol size. The dashed lines identify the intermediate times at which size distributions were calculated. 
correlation between the intensity changes of the difference bands at 1435 and $3428 \mathrm{~cm}^{-1}$ ( $\mathrm{OH}$ stretching vibration of $\mathrm{H}_{2} \mathrm{O}$ ) was found (Fig. 7C). In conclusion, the data indicate that the $\mathrm{H} / \mathrm{D}$ exchange in the protein surely concludes during the first phase, whereas an $\mathrm{H}-\mathrm{D}$ exchange in $\mathrm{D}_{2} \mathrm{O}$ molecules occurs during the second phase; this is an indirect indication of structural changes in protein molecules.

Other IR bands, in particular in the $1085-1105 \mathrm{~cm}^{-1}$ region and at $1725 \mathrm{~cm}^{-1}$, changed their intensity during the second phase of protein incubation (insets of Fig. S3 in Supplementary information). The bands at about $1100 \mathrm{~cm}^{-1}$ are due to vibrational modes of His and in particular to its cationic form $\left(\mathrm{His}^{+}\right)$and deuterated forms [51,52], whereas the $1725 \mathrm{~cm}^{-1}$ band is due to the vibrations of carboxylic group of Glu and Asp residues, making a single $\mathrm{H}$-bond $[52,53]$. The presence of metal ions (copper more than zinc) slightly cushioned the signal increase at $\sim 1085 \mathrm{~cm}^{-1}$ after $3 \mathrm{~h}$ of protein incubation (Fig. S4a in Supplementary data); this behavior indicates an increase in the His ${ }^{+}$ content after heating, in agreement with the Raman results, according to the order $\mathrm{BLG}<\mathrm{Cu}-\mathrm{BLG}<\mathrm{Zn}$-BLG (Table 1 ).

As regards the carboxylic vibration band at $1725 \mathrm{~cm}^{-1}$, its intensity change further evidences a charge re-distribution in the protein. This band was present before incubation only in the Zn-BLG sample, and increased in all samples during the second phase of the aggregation kinetics. The comparison of the time-evolution of all systems (Fig. S4b in Supplementary data) evidenced that the presence of $\mathrm{Zn}^{2+}$ ions in solution gives rise to a partial neutralization of the protein charge already at room temperature. After about 30 min of heating, zinc ions, as copper ions, promote the partial neutralization of the charge. Indeed, in the absence of metal ions, a slight increase in the $1725 \mathrm{~cm}^{-1}$ band was still observed, but after $3 \mathrm{~h}$ of heating.

\subsection{Effects of metal ions on aggregate growth}

The time evolution of the aggregation process of BLG and the two metal-BLG systems was followed by dynamic light scattering kinetic studies. BLG resulted to assemble into supramolecular structures at neutral $\mathrm{pH}$ after about 60-90 min and the mean diameter of the aggregates was about $25 \mathrm{~nm}$ after $400 \mathrm{~min}$ (Fig. 8).

The addition of metal ions to the BLG solution modulated the aggregation evolution. In the presence of $\mathrm{Cu}^{2+}$ ions, the aggregation process was activated immediately after the incubation and with a higher rate, although aggregates had a mean diameter similar to that of those formed in the solution of BLG alone (Fig. 8B). However, the higher scattered intensity of the signal indicated a more numerous formation of aggregated species. As regards $\mathrm{Zn}^{2+}$ ions, their presence led to the formation of larger supramolecular structures, although a good overlapping in the evolution of the scattered intensity and in the mean diameter signals was revealed for Cu-BLG and Zn-BLG samples within the first $50 \mathrm{~min}$ (Fig. 8A). The class separation of the species in solution depending on their dimensions was also obtained on the basis of the light scattered intensity at four times, from 0 to $400 \mathrm{~min}$. As expected, only native species of the protein were initially revealed and only in the BLG sample they didn't disappear at the end of the protein incubation (Fig. 9A).
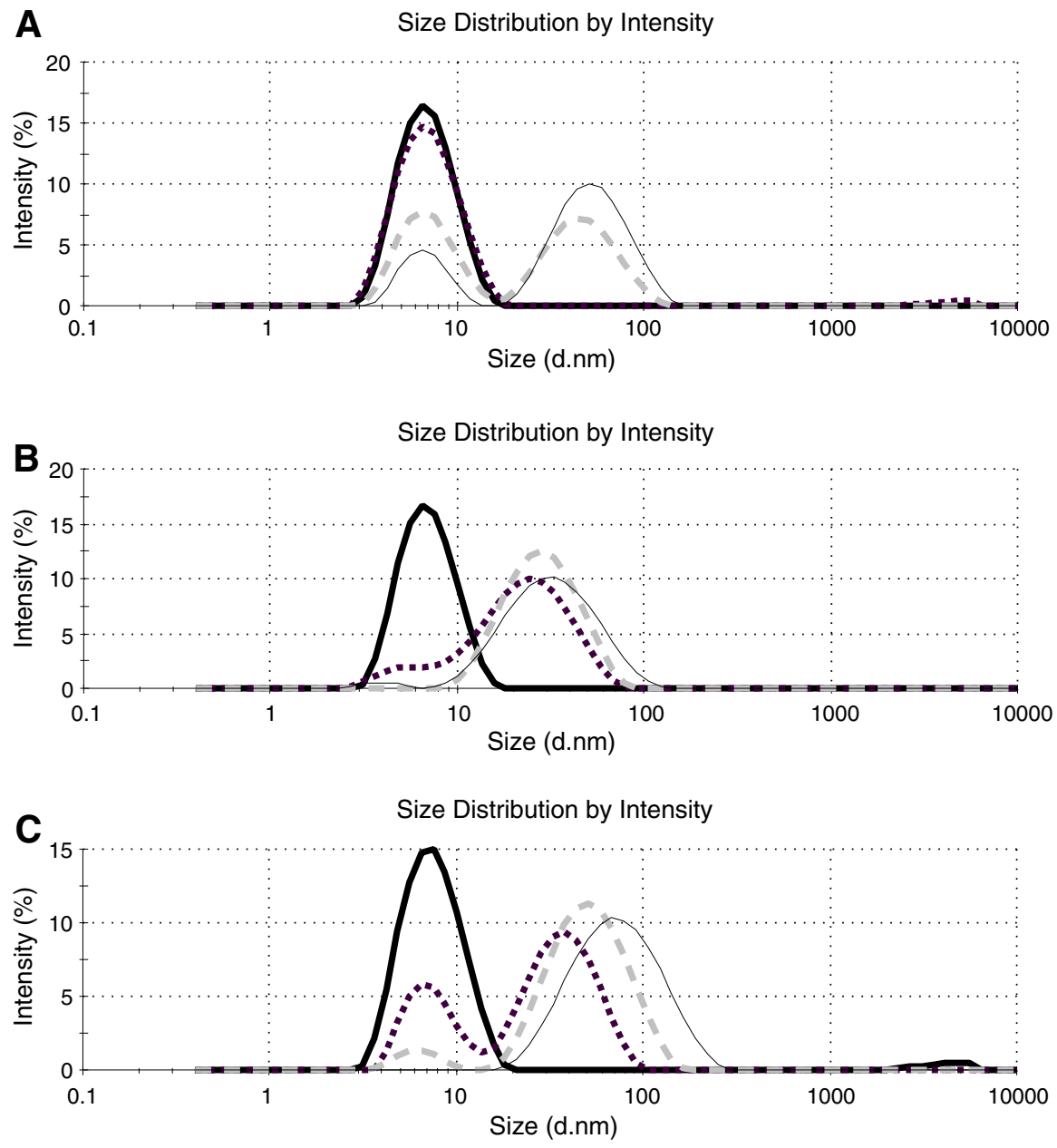

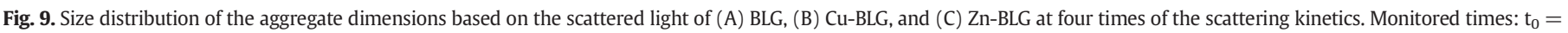

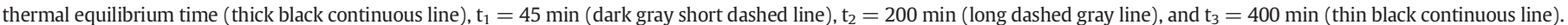




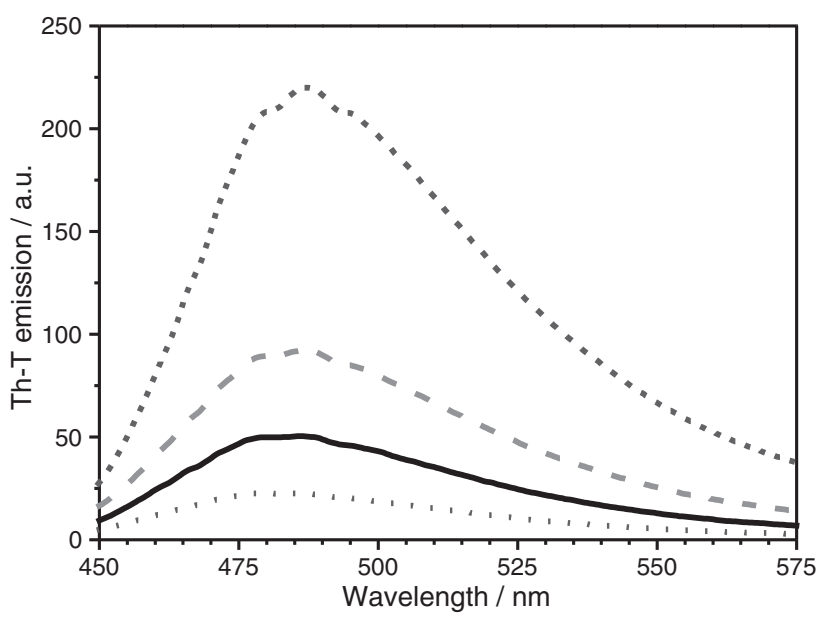

Fig. 10. Emission of Th-T in native BLG (black pointed line), heated BLG (black continuous line), heated Cu-BLG (dark gray short dashed line), heated Zn-BLG (gray long dashed line). Excitation at $440 \mathrm{~nm}$. Protein and Th-T concentration: $33 \mu \mathrm{M}$ and $40 \mu \mathrm{M}$, respectively.

The presence of copper ions made the conversion of the native species in aggregated structures more rapid than in BLG and Zn-BLG, in agreement with the literature [45]. Indeed, after 45 and $200 \mathrm{~min}$, a more significant decrease in native species was evident in Cu-BLG than in BLG and Zn-BLG and, simultaneously, a higher increase in the number of aggregated species took place. The distribution of the aggregated species resulted slightly different in the three systems at the end of the thermal incubation: species with the lowest diameter (about $25 \mathrm{~nm}$ ) was found in the Cu-BLG system, followed by BLG (about $50 \mathrm{~nm}$ ) and Zn-BLG (about $65 \mathrm{~nm}$ ). This is in agreement with the literature data reporting that small molecular species have been revealed in the presence of $\mathrm{Cu}^{2+}$ ions [33]. The formation of bigger species of about 50-65 nm diameter in the presence of $\mathrm{Zn}^{2+}$ ions agrees well with the Raman results, suggesting that $\mathrm{Zn}^{2+}$ ions are more efficient than $\mathrm{Cu}^{2+}$ in affecting the re-distribution of charges in the protein and, as a consequence, in promoting protein aggregation.

In conclusion, the dynamic light scattering experiments evidenced that both metal ions promote the heat-induced BLG aggregation but different protein aggregation pathways are followed, as shown by the substitution of large aggregates formed on heating in the presence of $\mathrm{Zn}^{2+}$ by smaller molecular species in the presence of $\mathrm{Cu}^{2+}$.

\subsection{Effects of metal ions on aggregate morphology}

In order to test the eventual formation of cross-beta structures, Th-T dye, a probe of fibrillar growth in solution during thermal incubation, was added to the solutions at room temperature after the kinetics. As a consequence of the thermal treatment, a marked increase in the Th-T emission was obtained for all systems (Fig. 10); this effect was particularly evident in the presence of $\mathrm{Cu}^{2+}$ ions, indicating the formation of a greater number of cross-beta structures during the thermal incubation. This result is in agreement with the IR data, indicating a higher growth of $\beta$-aggregated structures in Cu-BLG than in BLG and Zn-BLG.

To investigate the morphology of the aggregated structures originated by the incubation at $60{ }^{\circ} \mathrm{C}$ for $400 \mathrm{~min}$, AFM measurements were carried out. Meanly, oligomeric structures with a 30-50 nm diameter were imaged in BLG samples, as well as some fibril-like structures (Fig. 11). In particular, long fibrils were revealed both in the Cu-BLG and $\mathrm{Zn}$-BLG samples. In the former the fibril section measured about $25 \mathrm{~nm}$, whereas in the latter thermal incubation led to the formation of fibril-like linear aggregates, where oligomeric structures resulted piled up (Fig. 11(B) and (C)).

The section in the linear part of the aggregates was about $20 \mathrm{~nm}$, and the diameter of the visible oligomers in fibril-like aggregates was about $50 \mathrm{~nm}$. These findings are consistent with the results obtained by the analysis of the light scattering measurements. Moreover, in the Zn-BLG system the presence of branched fibrils was detected, as well as a bigger section in the linear part of the aggregates, maybe caused by the different re-distribution of protein charges promoted by $\mathrm{Zn}^{2+}$ ions.

These results further confirm that when metal ions are present during the protein thermal treatment, the formation of larger species, auto-assembling in fibrils, is favored, but the final morphology of the assembled species depends on the metal.

\section{Conclusions}

Different techniques were used to analyze the heat-induced modifications of metal-BLG systems and to investigate the related molecular mechanisms. The changes in His protonation and the formation of stronger hydrogen bonds between $\mathrm{OH}$ groups (Tyr residues) and negatively charged acceptors (Glu and Asp residues) have evidenced the primary importance of the protein charge distribution during the aggregation process. This re-distribution of charges is favored by both $\mathrm{Cu}^{2+}$ and $\mathrm{Zn}^{2+}$ ions, but it is more relevant in the presence of $\mathrm{Zn}^{2+}$ ions, which are able to slightly alter the BLG natural state, by favoring the more opened S-S configurations and increasing the $\beta$-sheet content just before heating. Of consequence, also hydrophobic interactions are slightly modified, as suggested by the Trp micro-environment changes. On the basis of these results and the literature, His161 and Trp61 residues, as well as the Cys66-Cys160 disulfide bridge, have resulted to be reasonably involved in the BLG aggregation process.

The capability of $\mathrm{Zn}^{2+}$ ions to slightly modify the secondary and tertiary structure of the BLG natural state, differently from $\mathrm{Cu}^{2+}$ ions which are partially bound to the native BLG, may be a key step to understand the different effects of the two metal ions on the protein aggregation process. The slight unfolding caused by $\mathrm{Zn}^{2+}$ before heating and the more relevant redistribution of charges, giving rise to a different screening of electrostatic interactions between charged BLG molecules, favor the formation of bigger aggregates and branched fibril-like structures.

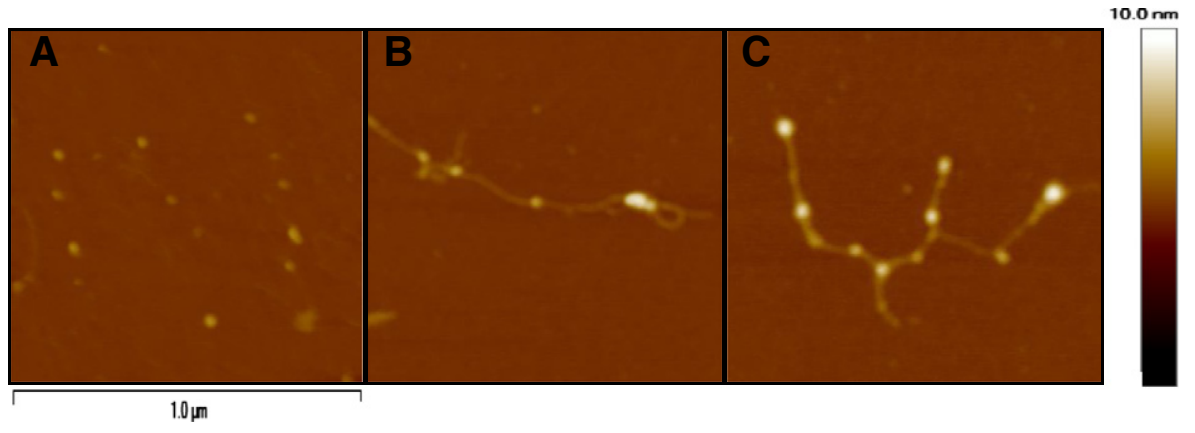

Fig. 11. AFM images (height data) of BLG (A), Cu-BLG (B), Zn-BLG (C) after incubation at $60{ }^{\circ} \mathrm{C}$ for 400 min. Images were obtained at room temperature. 
On the contrary, $\mathrm{Cu}^{2+}$ ions play a relevant role only during the heating treatment by activating, immediately after incubation, the aggregation evolution, increasing the aggregation rate and favoring the formation both of a higher number of aggregated species and a higher growth of cross-beta structures.

Moreover, the study of thermal kinetics has allowed us to understand that the BLG aggregation process at neutral $\mathrm{pH}$ occurs by two phases. The first one is characterized by partial unfolding, conformational changes and aggregate growth, forming oligomers and protofibrils, whereas the second phase depends on the aggregation state in solution and not on the protein single molecule conformation, and is characterized by further supramolecular assembly, leading to the formation of fibrils.

In conclusion, these findings indicate that the chemical and physical approach in studying structural changes in proteins, caused by external factors such as metal addition and heating treatment, is successful. In fact, the combination of different techniques such as Raman, IR and $\mathrm{H}-\mathrm{D}$ exchange experiments, as well as AFM, has allowed us to identify the main amino acid residues involved in the protein stabilization and the different role played by $\mathrm{Zn}^{2+}$ and $\mathrm{Cu}^{2+}$ ions in the molecular mechanisms that give rise to a different final morphology of the aggregated species.

\section{Abbreviation}

AFM atomic force microscopy

BLG bovine beta-lactoglobulin A

DLS dynamic light scattering

ggg gauche-gauche-gauche $\mathrm{S}-\mathrm{S}$ conformation

ggt gauche-gauche-trans $\mathrm{S}-\mathrm{S}$ conformation

tgt trans-gauche-trans S-S conformation

IR infrared

Th- $\mathrm{T}$ thioflavin $\mathrm{T}$

\section{Appendix A. Supplementary data}

Supplementary data to this article can be found online at http://dx. doi.org/10.1016/j.jinorgbio.2014.04.003.

\section{References}

[1] C.M. Dobson, Philos. Trans. R. Soc. B 356 (2001) 133-145.

[2] V.N. Uversky, A.L. Fink, Biochim. Biophys. Acta 1698 (2004) 131-153.

[3] M.D. Kirkitadze, G. Bitan, D.B. Teplow, J. Neurosci. Res. 69 (2002) 567-577.

[4] M. Bucciantini, E. Giannoni, F. Chiti, F. Baroni, L. Formigli, J. Zurdo, N. Taddei, G. Ramponi, C.M. Dobson, M. Stefani, Nature 416 (2002) 507-511.

[5] W.S. Gosal, S.B. Ross-Murphy, Curr. Opin. Colloid Interface Sci. 5 (2000) 188-194.

[6] V. Vetri, F. Librizzi, V. Militello, M. Leone, Eur. Biophys. J. 36 (2007) 733-741.

[7] G. Navarra, D. Giacomazza, M. Leone, F. Librizzi, V. Militello, P.L. San Biagio, Eur. Biophys. J. 38 (2009) 437-446.

[8] G. Kontopidis, C. Holt, L. Sawyer, J. Dairy Sci. 87 (2004) 785-796.
[9] K. Kuwata, R. Shastry, H. Cheng, M. Hoshino, C.A. Batt, Y. Goto, H. Roder, Nat. Struct. Biol. 8 (2001) 151-155.

[10] R. Carrotta, R. Bauer, R. Waninge, C. Rischel, Protein Sci. 10 (2001) 1312-1318.

[11] W.L. Chen, M.T. Huang, C.Y. Liau, J.C. Ho, K.C. Hong, S.J.T. Mao, J. Dairy Sci. 88 (2005) 1618-1630.

[12] G. Navarra, M. Leone, V. Militello, Biophys. Chem. 131 (2007) 52-61.

[13] R. Carrotta, L. Arleth, J.S. Pedersen, R. Bauer, Biopolymers 70 (2003) 377-390.

[14] S.M. Fitzsimons, D.M. Mulvihill, E.R. Morris, Food Hydrocoll. 21 (2007) 638-644.

[15] L.N. Arnaudov, R. de Vries, H. Ippel, C.P.M. van Mierlo, Biomacromolecules 4 (2003) 1614-1622.

[16] K. Suzuki, T. Miura, H. Takeuchi, Biochem. Biophys. Res. Commun. 285 (2001) 991-996.

[17] G. Navarra, A. Tinti, M. Leone, V. Militello, A. Torreggiani, J. Inorg. Biochem. 103 (2009) 1729-1738.

[18] B.J. Harvey, E. Bell, L. Brancaleon, J. Phys. Chem. B 111 (2007) 2610-2620.

[19] R. Ipsen, J. Otte, K.B. Ovist, J. Dairy Res. 68 (2001) 277-286.

[20] T. Miura, K. Suzuki, N. Kohata, H. Takeuchi, Biochemistry 39 (2000) 7024-7031.

[21] D. Religa, D. Strozyk, R.A. Cherny, I. Volitakis, V. Haroutunian, B. Winblad, J. Naslund, A.I. Bush, Neurology 67 (2006) 69-75.

[22] M. Hashimoto, E. Masliah, Brain Pathol. 9 (1999) 707-720.

[23] A.T. Tu, in: R.J.H. Clark, R.E. Hester (Eds.), Advances in Spectroscopy, Spectroscopy of Biological Systems, vol. 13, Wiley, Chichester, United Kingdom, 1986, pp. 47-112.

[24] Z. Jurasekova, G. Marconi, S. Sanchez-Cortes, A. Torreggiani, Biopolymers 11 (2009) 917-927.

[25] R. Tuma, J. Raman Spectrosc. 36 (2005) 307-319.

[26] J. Bandekar, Vib. Spectrosc. 5 (1993) 143-173.

[27] A. Torreggiani, J. Domenech, S. Atrian, M. Capdevila, A. Tinti, Biopolymers 89 (2008) $1114-1124$

[28] Z. Jurasekova, A. Tinti, A. Torreggiani, Anal. Bioanal. Chem. 400 (2011) 2921-2931.

[29] J.M. Bakker, C. Plutzer, I. Hunig, T. Haber, I. Compagnon, G. von Helden, G. Meijer, K. Kleinermanns, ChemPhysChem 6 (2005) 120-128.

[30] V. Militello, C. Casarino, A. Emanuele, A. Giostra, F. Pullara, M. Leone, Biophys. Chem. 107 (2004) 175-187.

[31] H. Naiki, K. Higuchi, M. Hosokawa, T. Takeda, Anal. Biochem. 177 (1989) 244-249.

[32] S. Brownlow, J.H.M. Cabral, R. Cooper, D.R. Flower, S.J. Yewdall, I. Polikarpov, A.C.T. North, L. Sawyer, Structure 5 (1997) 481-495.

[33] M. Gulzar, T. Croguennec, J. Jardin, M. Piot, S. Bouhallab, Food Chem. 116 (2009) $884-891$.

[34] R. Floris, I. Bodnar, F. Weinbreck, A.C. Alting Int Dairy J. 18 (2008) 566-573.

[35] P.A. Frey, S.A. Whitt, J.B. Tobin, Science 264 (1994) 1927-1930.

[36] A.A. Hays, I.R. Vassiliev, J.H. Golbeck, R.J. Debus, Biochemistry 37 (1998) 11352-11365.

[37] A. Torreggiani, S. Bonora, G. Fini, Biopolymers 57 (2000) 352-364.

[38] A. Torreggiani, M. Tamba, G. Fini, Biopolymers 57 (2000) 19-27.

[39] H. Takeuchi, Biopolymers 72 (2003) 305-317.

[40] I. Ashikawa, K. Itoh, Biopolymers 18 (1979) 1859-1876

[41] J. Gerbrand Mesu, T. Visser, F. Soulimani, B.M. Weckhuysen, Vib. Spectrosc. 39 (2005) 114-125.

[42] A. Torreggiani, M. Tamba, S. Bonora, G. Fini, Biopolymers 72 (2003) 290-298.

[43] A. Torreggiani, A.D. Esposti, M. Tamba, G. Marconi, G. Fini, J. Raman Spectrosc. 37 (2006) 291-298.

[44] A. Torreggiani, J. Domenech, A. Tinti, J. Raman Spectrosc. 40 (2009) 1687-1693.

[45] A. Stirpe, B. Rizzuti, M. Pantusa, R. Bartucci, L. Sportelli, L. Guzzi, Eur. Biophys. J. 37 (2008) 1351-1360.

[46] G. Verdone, A. Corazza, P. Viglino, F. Pettirossi, S. Giorgetti, P. Mangione, A. Andreola, M. Stoppini, V. Bellotti, G. Esposito, Protein Sci. 11 (2002) 487-499.

[47] A. Torreggiani, C. Fagnano, G. Fini, J. Raman Spectrosc. 28 (1997) 23-27.

[48] A. Torreggiani, M. Tamba, I. Manco, M.R. Faraone-Mennella, C. Ferreri, C. Chatgilialoglu, J. Mol. Struct. 744-747 (2005) 767-773.

[49] T. Kitagawa, T. Azuma, K. Hamaguchi, Biopolymers 18 (1979) 451-465.

[50] A. Dong, J. Matsuura, S. Dean Allison, E. Chrisman, M.C. Manning, J.F. Carpenter, Biochemistry 35 (1996) 1450-1457.

[51] T. Noguchi, Y. Inoue, X.-S. Tang, Biochemistry 38 (1999) 10187-10195.

[52] A. Barth, Prog. Biophys. Mol. Biol. 74 (2000) 141-173.

[53] S.Y. Venyaminov, N.N. Kalnin, Biopolymers 30 (1990) 1243-1257 